\title{
Proximal aortic compliance and diastolic function assessed by speckle tracking imaging
}

\section{La compliance de l'aorte proximale et la fonction diastolique évaluées par imagerie de suivi de pixel}

\author{
Alexander J. Gregory, MD • Gary Dobson, MD
}

Received: 14 August 2012/Accepted: 9 April 2013/Published online: 23 April 2013

(C) Canadian Anesthesiologists' Society 2013

\begin{abstract}
Purpose Speckle tracking imaging (STI) is a recent technique that evaluates an echocardiographic image throughout the cardiac cycle and provides dynamic variables such as tissue velocities and strain rates. The objective of our study was to determine 1) if STI can be used to quantify proximal aortic compliance and 2) if decreased aortic compliance determined by STI will reproduce the previously reported correlation with diastolic function.

Methods This was a retrospective observational case series using previously obtained intraoperative transesophageal images. Diastolic performance was quantified by STI-based longitudinal velocities of the basal-septal and basal-lateral walls of the left ventricle in early diastole ( $L V$ $\left.E^{\prime}\right)$. Change in proximal aortic volume was calculated using STI to measure peak longitudinal and radial velocities in early diastole. After normalizing for mean arterial pressure, compliance was calculated and then compared with basal-septal and basal-lateral LV $E^{\prime}$ using single regression analysis.
\end{abstract}

This article is accompanied by an editorial. Please see Can J Anesth 2013; 60: this issue.

Author contributions Alexander J. Gregory and Gary Dobson have made substantial contributions to the conception and design of the study, acquisition of data or analysis and interpretation of data, and drafting the article or revising it critically for important intellectual content.

A. J. Gregory, MD $(\bowtie) \cdot$ G. Dobson, MD

Department of Anesthesia, Faculty of Medicine, University of

Calgary, Room C229, Foothills Medical Centre, 1403-29 ST

NW, Calgary, AB T2N 2T9, Canada

e-mail: alexg27x@telus.net
Results Twenty patients were included in our analysis. Linear regression of basal-septal $L V E^{\prime}$ and basal-lateral $L V E^{\prime}$ vs proximal aortic compliance during diastole each resulted in an $R^{2}$ value of $0.26(P<0.05)$.

Conclusion Speckle tracking can be used to describe the physical motion of the aortic wall and to calculate its compliance. We confirm that variation in diastolic function can be attributed, in part, to aortic compliance. Our novel approach of measuring compliance throughout the cardiac cycle, isolating radial and longitudinal contributions, and evaluating previously obtained images retrospectively provides advantages over previously reported measures of aortic compliance. Speckle tracking promises new insights into ventricular function, aortic mechanics, and the interaction between these structures.

\section{Résumé}

Objectif L'imagerie de suivi de pixel, ou speckle tracking imaging (STI) en anglais, est une technique récente qui permet d'évaluer une image échocardiographique tout au long du cycle cardiaque et d'obtenir des variables dynamiques telles que les velocités tissulaires et les vitesses de déformation. L'objectif de notre étude était de déterminer si 1) la STI pouvait être utilisée pour quantifier la compliance de l'aorte proximale, et si 2) une compliance aortique réduite telle que déterminée par la STI reproduisait la correlation avec la fonction diastolique rapportée précédemment.

Méthode Cette étude est une série de cas observationnelle rétrospective se fondant sur des images transosophagiennes peropératoires obtenues par le passé. La performance diastolique a été quantifiée par les velocités longitudinales fondées sur la STI des parois basales septales et basales latérales du ventricule gauche en début de diastole ( $\left.L V E^{\prime}\right)$. Les changements de volume de l'aorte proximale ont été calculés à l'aide de la STI afin de mesurer les vélocités 
longitudinales et radiales maximales en début de diastole. Après normalisation pour tenir compte de la tension artérielle moyenne, la compliance a été calculée puis comparée aux LV $E^{\prime}$ basales septales et basales latérales à l'aide d'une analyse par régression unique.

Résultats Vingt patients ont été inclus dans notre analyse. La régression linéaire des $L V E^{\prime}$ basales septales et basales latérales vs. la compliance de l'aorte proximale pendant la diastole était une valeur $R^{2}$ de $0,26(P<0,05)$ dans les deux cas.

Conclusion Le suivi de pixel peut être utilisé pour décrire le mouvement physique de la paroi aortique et pour calculer sa compliance. Nous confirmons que la variation de la fonction diastolique peut être attribuée, en partie, à la compliance aortique. Notre approche innovante, qui consiste à mesurer la compliance tout au long du cycle cardiaque, en isolant les contributions radiales et longitudinales, et à évaluer de façon rétrospective des images obtenues par le passé, offre des avantages par rapport aux mesures de la compliance aortique précédemment rapportées. Le suivi de pixel est un outil prometteur pour découvrir plus en détail la fonction ventriculaire, les mécanismes de l'aorte, et l'interaction entre ces structures.

Left ventricular diastolic dysfunction has been recently reviewed in the literature and is associated with increased perioperative morbidity in cardiac, vascular, and other noncardiac surgery. ${ }^{1-6}$ Using various methods of measurement, decreased aortic compliance has been previously shown to correlate with diastolic dysfunction. ${ }^{7-12}$ Speckle tracking imaging (STI) is a recent technique that evaluates an echocardiographic image throughout the cardiac cycle and provides dynamic variables such as tissue velocities and strain rates. It provides potential advantages over Dopplerbased techniques and has been used successfully to quantify left ventricular diastolic function. ${ }^{13-16}$ Though STI was initially developed to assess ventricular function, STI technology has also been used to evaluate the elastic properties of the carotid artery and the thoracic and abdominal aorta. ${ }^{17-19}$ To date, studies attempting to use STI to measure proximal aortic compliance are lacking. The objective of our study was to determine 1) if STI can be used to quantify proximal aortic compliance and 2) if decreased aortic compliance determined by STI will reproduce a previously reported correlation with diastolic function.

\section{Methods}

This was a retrospective observational case series approved by the University of Calgary Research Ethics Board. Sample size was calculated using a previous study where the thoracic aorta was analyzed with speckle tracking. ${ }^{18}$ In this study the authors reported a mean (standard deviation [SD]) rate of change for the cross section $(\mathrm{dA} / \mathrm{dt})$ to be 3.1 (1.0) $\mathrm{cm}^{2} \cdot \mathrm{sec}^{-1}$ and $7.5(3.5) \mathrm{cm}^{2} \cdot \mathrm{sec}^{-1}$ for patients with aortic stenosis and aortic insufficiency, respectively. Taking the lower of the two means would result in a mean (SD) radial velocity of $0.40(0.13) \mathrm{cm} \cdot \mathrm{sec}^{-1}$. If the ascending aorta's radial velocity were similar, then a sample size of 21 patients would allow a measurement error of $0.05 \mathrm{~cm} \cdot \mathrm{sec}^{-1}$ or $15 \%$. $\left(\operatorname{SPSS}^{\circledR}\right.$ SamplePower $^{\circledR}$, Version 3, IBM, Armonk, NY, USA) Though this margin of error may seem high, we considered a margin of error of $0.05 \mathrm{~cm} \cdot \mathrm{sec}^{-1}$ sufficient because we would be measuring larger peak velocities instead of mean velocities.

Transesophageal echocardiographic (TEE) images from January 2006 to December 2010 were obtained from a computer database storing previously acquired intraoperative studies from non-cardiac surgeries performed at the Peter Lougheed Hospital in Calgary, Alberta. All images had been acquired using a GE Vivid 7 TEE machine, and analysis was performed offline on a PC workstation (EchoPAC, Version 7.2.0, GE Vinmed, Horton, Norway). Studies were selected from the database in chronological order starting with the oldest available study. The exclusion criteria were: severe left ventricular systolic dysfunction, regional wall motion hypokinesis in the segments being analyzed, severe aortic valve pathology (insufficiency or regurgitation), inadequate TEE views, and insufficient TEE image quality for STI analysis.

Left ventricular diastolic performance was quantified from the standard TEE mid-esophageal four-chamber view. Speckle tracking imaging-based longitudinal velocities of the basal-septal and basal-lateral walls of the left ventricle in early diastole ( $\left.\mathrm{LV} \mathrm{E}^{\prime}\right)$ were used to quantify diastolic function.

Aortic compliance is the change in volume resulting from a change in pressure. Its rate of change can be approximated by the quotient of the derivatives of both volume and pressure with respect to time (formula 1). In addition, by modelling the ascending aorta as a cylinder (formula 2), its derivative with respect to time (dV/dt) can be calculated (formula 3 ). The values for length (L) and radius ( $r$ ) were measured as described below. As the aorta contracts in diastole, its maximum rate of volume change $\left(\mathrm{dV} / \mathrm{dt}_{\max }\right)$ is approximated the maximal rates of change in both length $\left(\mathrm{dL} / \mathrm{dt}_{\max }\right)$ and radius $\left(\mathrm{dr} / \mathrm{dt}_{\max }\right)$ (formula 4$)$. These maximum, or peak, velocities were obtained using STI analysis as described below.

(1) $\mathrm{dV} / \mathrm{dP} \approx(\mathrm{dV} / \mathrm{dt}) /(\mathrm{dP} / \mathrm{dt})$

(2) $\mathrm{V}=\mathrm{L} \cdot \pi \cdot \mathrm{r}^{2}$

(3) $\mathrm{dV} / \mathrm{dt}=\left(\mathrm{dL} / \mathrm{dt} \cdot \pi \mathrm{r}^{2}\right)+(\mathrm{L} \cdot 2 \pi \mathrm{r} \cdot \mathrm{dr} / \mathrm{dt})$

(4) $\mathrm{dV} / \mathrm{dt}_{\max }=\left(\mathrm{dL} / \mathrm{dt}_{\max } \cdot \pi \mathrm{r}^{2}\right)+\left(\mathrm{L} \cdot 2 \pi \mathrm{r} \cdot \mathrm{dr} / \mathrm{dt}_{\max }\right)$ 
Measurements of proximal aortic dimensions were taken from the standard TEE mid-esophageal aortic long-axis view. The aorta was divided into two segments. The first segment was the aortic root. Its anterior and posterior lengths were measured as two straight lines spanning, but not including, the walls of the sinus of Valsalva from the aortic valve to the sinotubular junction. The second segment was measured as two straight lines along the anterior and posterior aortic walls from the sinotubular junction extending $2 \mathrm{~cm}$ into the ascending aorta. The lengths of the second segment were shortened in the event of poor image quality or if the boundary of the image prevented a full $2-\mathrm{cm}$ segment. The segments were averaged to obtain a single length for our calculation of $\mathrm{dV} / \mathrm{dt}_{\max }$. The diameter of each segment was taken, wall to wall, at the midpoint of the segment (Fig. 1). All measurements were taken at end systole.

Measurements of aortic wall velocities were taken from the standard TEE mid-esophageal aortic long-axis view. Using the STI software, the anterior and posterior walls were traced from the aortic valve along the sinus of Valsalva and onto the ascending aorta until the image border was reached. The region of interest was made as small as possible to include only the aortic wall. The borders of the speckle tracking sections were adjusted to match the previously measured segments. A full cine loop was observed to ensure the aortic walls were appropriately tracked throughout the cardiac cycle. Speckle tracking analysis was performed, and the early diastolic peak radial and longitudinal velocities were identified for the anterior and posterior walls of both segments (Figs. 2 and 3). Image analysis was performed by one investigator (A.J.G.).

The value for $\mathrm{dP} / \mathrm{dt}$ cannot be estimated accurately without a simultaneous arterial tracing, which was not possible in our study. Arterial compliance derived from the exponential decay of aortic waveforms is known to vary inversely with mean arterial blood pressure ${ }^{20}$; therefore,
$\mathrm{dV} / \mathrm{dt}$ was normalized to mean arterial pressure to approximate aortic compliance. The value for mean blood pressure was obtained by synchronizing the time displayed on the TEE image with the mean arterial pressure as recorded on the electronic anesthetic record at the identical time.

Aortic compliance for the purpose of correlation with diastolic function was defined as the maximum rate of change in proximal aortic compliance during diastole $\left(\mathrm{C}_{\mathrm{d}-\max }\right)$. The maximum aortic compliance during diastole was separately calculated for both segments $\left(\mathrm{C}_{\mathrm{d}-\max 1}\right.$ and $\mathrm{C}_{\mathrm{d}-\max 2}$ ). The single value for $\mathrm{C}_{\mathrm{d} \text {-max }}$ was then obtained by treating the two segments as a series (formula 5). The relationship of $\mathrm{C}_{\mathrm{d}-\max }$ and left ventricular diastolic function was determined using linear regression analysis.

$$
\mathrm{C}_{\mathrm{d}-\max }=\left(\left(1 / \mathrm{C}_{\mathrm{d}-\max 1}\right)+\left(1 / \mathrm{C}_{\mathrm{d}-\max 2}\right)\right)^{-1}
$$

Full STI analysis, including aortic wall tracing, was repeated more than one year later. One investigator repeated the analysis (A.J.G.) while the other performed it for the first time (G.D.). Pearson correlation coefficients and Bland-Altman plots were used to assess for inter- and intraobserver reproducibility and bias for calculating the value of $\mathrm{dV} / \mathrm{dt}_{\max }{ }^{21,22}$ All statistical analysis was performed using Analyse-it ${ }^{\circledR}$ software (Analyse-It, version 2.24, Analyse-it Software Ltd., Leeds, UK).

\section{Results}

Thirty-two consecutive studies were reviewed prior to achieving the 21 patients with adequate images to include in our analysis. Subsequently, STI analysis was unable to be reliably performed on one subject's images, resulting in outlier values greater than two standard deviations from the mean values of the group. The investigators determined that the TEE image quality was insufficient and the
Fig. 1 Caliper measurements of the ascending aorta used to calculate compliance. Taken from the mid-esophageal longaxis view of the aorta at endsystole. $\mathrm{A} 1=$ posterior length of segment 1 (aortic root); $\mathrm{A} 2=$ anterior length of segment $1 ; \mathrm{B} 1=$ posterior length of segment 2 (ascending aorta); $\mathrm{B} 2=$ anterior length of segment $2 ; \mathrm{C}=$ segment 1 diameter; $\mathrm{D}=$ segment 2 diameter. See Methods section for details
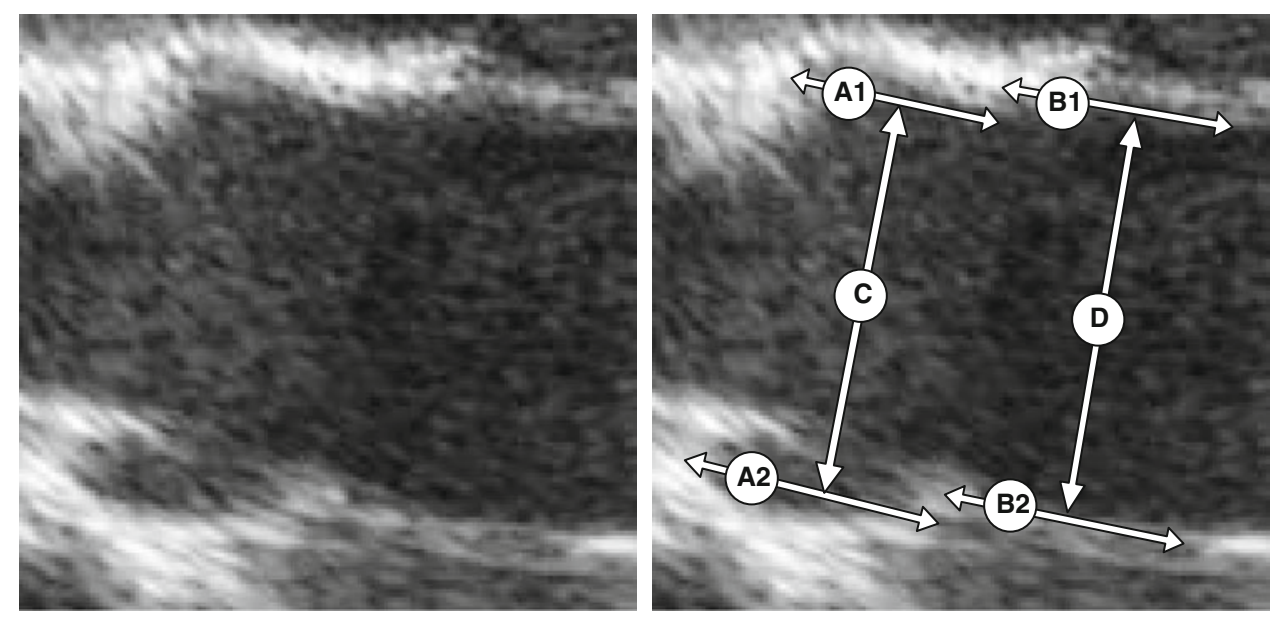


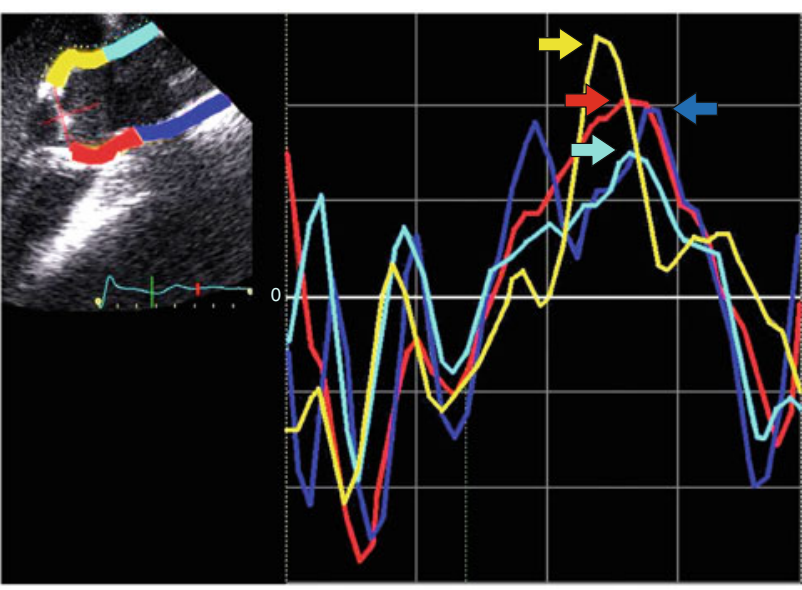

Fig. 2 Example of speckle tracking image to obtain aortic longitudinal velocity data. $\mathrm{X}$-axis depicts time $(\mathrm{msec})$ starting in systole. $\mathrm{Y}$-axis depicts velocity $\left(\mathrm{cm} \cdot \mathrm{sec}^{-1}\right)$. Each colour corresponds with a particular segment of the aorta: yellow $=$ posterior root; red $=$ anterior root; $\quad$ cyan $=$ posterior ascending aorta; blue $=$ anterior ascending aorta. Maximum values for longitudinal velocities (shown with arrows) were used to calculate maximum diastolic compliance

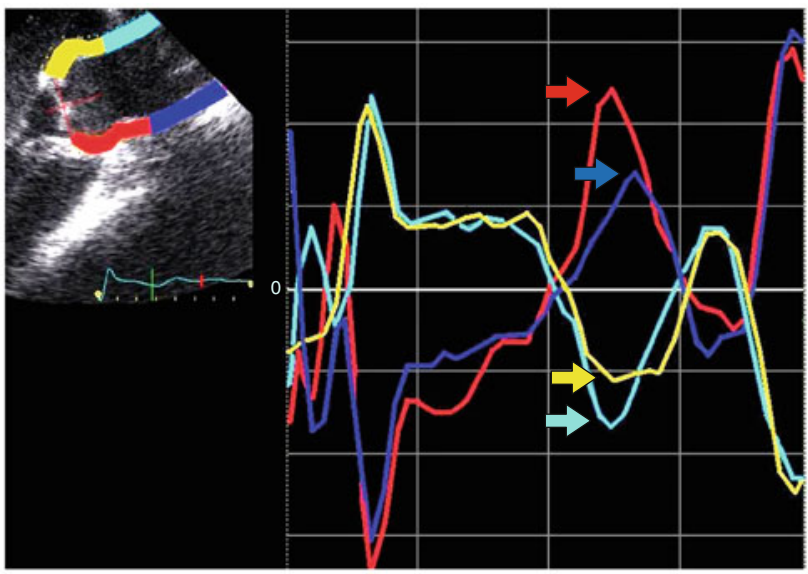

Fig. 3 Example of speckle tracking image to obtain aortic radial velocity data. $\mathrm{X}$-axis depicts time $(\mathrm{msec})$ starting in systole. Y-axis depicts velocity $\left(\mathrm{cm} \cdot \mathrm{sec}^{-1}\right)$. Each colour corresponds to a particular segment of the aorta: yellow $=$ posterior root; red $=$ anterior root; cyan $=$ posterior ascending aorta; blue $=$ anterior ascending aorta. Maximum values for radial velocities (shown with arrows) were used to calculate maximum diastolic compliance

software was improperly tracking the aortic walls. This patient's data were excluded from analysis, resulting in 20 patients being included in our results.

General patient characteristics are summarized in Table 1. Mean (standard deviation [SD]) LV E' velocities of the basal-septal and basal-lateral walls were 4.48 (1.50) $\mathrm{cm} \cdot \mathrm{sec}^{-1}$ and $5.22(1.90) \mathrm{cm} \cdot \mathrm{sec}^{-1}$, respectively. The data on the average radial velocities, longitudinal velocities, radii, and lengths are included in Table 2. The maximum diastolic compliance of the series had a mean (SD) value of $0.85(0.35) \mathrm{mL} \cdot \mathrm{mmHg}^{-1} \cdot \mathrm{sec}^{-1}$. Linear regression of both the basal-septal $\mathrm{LV}^{\prime}$ and basal-lateral $\mathrm{LV}^{\prime} \mathrm{E}^{\prime} v s$ the maximum rate of change in proximal aortic compliance during diastole resulted in $\mathrm{R}^{2}$ values of $0.26(P<0.05)$ (see Figs. 4 and 5).

The inter-observer correlation coefficient for calculating $\mathrm{dV} / \mathrm{dt}_{\max }$ using our method was 0.96 with a bias of $-1.3 \%$ (range $-6.2 \%$ to $3.6 \% ; P=0.60$ ). The intra-observer correlation coefficient for $\mathrm{dV} / \mathrm{dt}_{\max }$ was 0.95 with a bias of $2.7 \%$ (range $-2.0 \%$ to $7.4 \% ; P=0.26$ ).

\section{Discussion}

We show that speckle tracking imaging appears to provide a reliable measurement of the radial and longitudinal velocities of the proximal aortic walls. Furthermore, it has the potential to describe the physical behaviour of the aorta and to calculate its compliance. Our results confirm the previously reported association between aortic compliance and diastolic function, with as much as $25 \%$ of the variation in myocardial velocity during diastole being attributed to aortic compliance. This association introduces various clinical implications. For example inotropic, vasopressor and vasodilating agents, as well as regional anesthesia techniques, may indirectly impact diastolic performance by altering proximal aortic stiffness. Therapies for heart failure with preserved systolic function may work by increasing aortic compliance, in addition to other mechanisms. Finally, surgical interventions that decrease aortic compliance, such as aortic grafts or endovascular stents, may be detrimental to diastolic function. Therefore conclusions regarding the direct myocardial effects of any intervention must be made with consideration of simultaneous changes in aortic function.

This novel use of STI provides several advantages over previously reported methods of measuring arterial or aortic compliance, such as the beta stiffness, aortic strain, and distensibility indices. These indices are equations that rely on static data, such as end-systolic and end-diastolic diameter or systolic and diastolic blood pressure. ${ }^{23,24}$ They result in a single indexed value for compliance, whereas our method can evaluate compliance continuously over time. These indices are also unable to isolate and quantify the individual contributions of radial and longitudinal motion to aortic compliance. We consider our approach to allow for a more precise and nuanced study of aortic mechanics.

Another unique feature of our methodology is the use of noninvasive and previously acquired data. Images, like those required for our study, can be obtained from transthoracic or transesophageal echocardiographs and would be included in any standard comprehensive echocardiographic exam. Mean arterial pressure is also reliably obtained with a blood pressure cuff or arterial artery catheter and is 
Table 1 Patient demographics, comorbidities and chronic medications

\begin{tabular}{|c|c|}
\hline Age (yr) & $72(9.3)$ \\
\hline Sex ( $\%$ male $)$ & 81 \\
\hline BMI $\left(\mathrm{kg} \cdot \mathrm{m}^{-2}\right)$ & $29.9(11.9)$ \\
\hline \multicolumn{2}{|l|}{ Preoperative vital signs } \\
\hline $\mathrm{SBP}(\mathrm{mmHg})$ & $131.7(19.9)$ \\
\hline $\mathrm{DBP}(\mathrm{mmHg})$ & $69.9(15.1)$ \\
\hline MAP (mmHg) & $90.5(12.1)$ \\
\hline Heart rate (beats $\cdot \min ^{-1}$ ) & $74.8(16.8)$ \\
\hline \multicolumn{2}{|l|}{ ASA class $(\%)$} \\
\hline II & 6 \\
\hline III & 62 \\
\hline IV & 31 \\
\hline \multicolumn{2}{|l|}{ Lee RCRI class (\%) } \\
\hline 0 & 12 \\
\hline 1 & 19 \\
\hline 2 & 38 \\
\hline$>2$ & 31 \\
\hline \multicolumn{2}{|l|}{ Comorbidities (\%) } \\
\hline Hypertension & 88 \\
\hline Coronary artery disease & 63 \\
\hline Diabetes mellitus & 19 \\
\hline Dyslipidemia & 50 \\
\hline \multicolumn{2}{|l|}{ Preoperative medications (\%) } \\
\hline Beta-blockers & 38 \\
\hline Calcium channel antagonists & 25 \\
\hline ACEi/ARB & 56 \\
\hline Diuretics & 31 \\
\hline Statins & 50 \\
\hline Nitrates & 25 \\
\hline
\end{tabular}

Values are expressed as mean (standard deviation) or as percentage where indicated

$\mathrm{ACEi}=$ angiotensin-converting enzyme inhibitors; $\mathrm{ARB}=$ angiotensin-II receptor blockers; ASA $=$ American Society of Anesthesiologists physical status; $\mathrm{BMI}=$ body mass index; $\mathrm{DBP}=$ diastolic blood pressure; $\mathrm{MAP}=$ mean arterial pressure; $\mathrm{RCRI}=$ revised cardiac risk index; $\mathrm{SBP}=$ systolic blood pressure

recorded as part of a standard anesthetic record. This combination of noninvasive and retrospective analysis makes our approach versatile, cost-effective, and uncomplicated. Combined with our high inter- and intra-observer reproducibility and low bias, it has potential applicability in both clinical medicine and future research.

We chose left ventricular basal-septal and basal-lateral wall velocities as our measure of diastolic function for two reasons. First, it allowed for better isolation of the early diastolic component in order to compare it with the corresponding peak change in aortic volume. Second, quantification of diastolic function, as outlined in the
American Society of Echocardiography guidelines, requires measurements, such as tissue Doppler imaging (TDI) velocities, E/A ratios, and transmitral deceleration times. ${ }^{25}$ These measurements are not part of the recommended standard intraoperative TEE exam; they were not consistently included in our retrospective studies and were therefore unavailable. ${ }^{26}$ Since the principles of measuring wall velocity by STI are related to those for TDI, in our view, this further supported our choice. ${ }^{27}$

The relationship of mitral annulus velocities measured by TDI and STI have been compared and are related but not equivalent. ${ }^{28}$ Septal and lateral mitral annulus TDI velocities of $8.3(3) \mathrm{cm} \cdot \mathrm{sec}^{-1}$ and $11.0(4.9) \mathrm{cm} \cdot \mathrm{sec}^{-1}$, respectively, values in the normal range for the age group of that study, were found to correspond with STI velocities of $5.2(1.8) \mathrm{cm} \cdot \mathrm{sec}^{-1}$ and $5.5(2.1) \mathrm{cm} \cdot \mathrm{sec}^{-1}$, respectively, which are similar to our results. The correlation of TDI and STI velocities was poor, $(r=0.4$ and 0.3$)$ for the septal wall and lateral walls, respectively. This highlights that the two modalities are interrelated although they do have fundamental differences. Speckle tracking imaging parameters may be a more accurate representation of myocardial function. For example, an akinetic base attached to normal myocardium may result in normal TDI values but would have almost zero values for STI velocity, strain, and strain rates. This difference is apparent in studies where subjects with normal ejection fractions have impairments in left ventricular systolic contractility detected by STI. ${ }^{16,29}$ Studies using STI have focused on myocardial strain or strain rates as a measure of diastolic function. ${ }^{14-16}$ These values have also been recently correlated to the traditional measures of diastolic dysfunction in both normal and abnormal subjects. ${ }^{15}$ As such, future studies using STI for the purpose of describing diastolic parameters should include these measures.

Proposed mechanisms for the correlation of aortic stiffness and diastolic function include afterload induced changes in diastolic performance and neurohormonal effects. ${ }^{30-32}$ It is possible that the contribution of afterload is underestimated in our study. Many studies, including our own, utilize compliance of the aorta or large proximal arteries as measures of afterload. This does not account for the microvasculature's contribution to systemic vascular resistance or the effect of reflected pressure waves, both of which can alter effective left ventricular afterload. Association without causation must also be considered. Disease processes that impair diastolic function commonly co-exist with poor aortic compliance, such as coronary artery disease. Other diseases share pathophysiology that may independently cause both diastolic dysfunction and impaired aortic compliance, like diabetes mellitus or advancing age. It is likely that all of the above factors 
Table 2 Speckle tracking imaging data, caliper measurements, and calculated values from study patients' left ventricle and aorta

\begin{tabular}{lc}
\hline LV b-Septal E' $\left(\mathrm{cm} \cdot \mathrm{sec}^{-1}\right)$ & $4.48(1.50)$ \\
$\mathrm{LV}$ b-Lateral E $\left(\mathrm{cm} \cdot \mathrm{sec}^{-1}\right)$ & $5.22(1.90)$ \\
Radius AoRoot $(\mathrm{cm})$ & $1.4(0.18)$ \\
Radius AscAo $(\mathrm{cm})$ & $1.7(0.2)$ \\
Length AoRoot $(\mathrm{cm})$ & $1.9(0.3)$ \\
Length AscAo $(\mathrm{cm})$ & $1.7(0.32)$ \\
Diastolic dL/dt ${ }_{\max }$ AoRoot $\left(\mathrm{cm} \cdot \mathrm{sec}^{-1}\right)$ & $2.9(1.3)$ \\
Diastolic dL/dt ${ }_{\max }$ AscAo $\left(\mathrm{cm} \cdot \mathrm{sec}^{-1}\right)$ & $2.7(1.2)$ \\
Diastolic dr/dt ${ }_{\max }$ AoRoot $\left(\mathrm{cm} \cdot \mathrm{sec}^{-1}\right)$ & $6.5(2.5)$ \\
Diastolic dr/dt ${ }_{\max }$ AscAo $\left(\mathrm{cm} \cdot \mathrm{sec}^{-1}\right)$ & $6.3(2.3)$ \\
Diastolic dV/dt $\mathrm{dt}_{\max }$ AoRoot $\left(\mathrm{mL} \cdot \mathrm{sec}^{-1}\right)$ & $128.0(53.1)$ \\
Diastolic dV/dt ${ }_{\max }$ AscAo $\left(\mathrm{mL} \cdot \mathrm{sec}^{-1}\right)$ & $147.1(57.0)$ \\
Maximum diastolic compliance $\left(\mathrm{mL} \cdot \mathrm{mmHg}^{-1} \cdot \mathrm{sec}^{-1}\right)$ & \\
AoRoot, $C_{\mathrm{d}-\max 1}$ & $1.64(0.78)$ \\
AscAo, $C_{\mathrm{d}-\max 2}$ & $1.86(0.78)$ \\
Series, $C_{\mathrm{d}-\max }$ & $0.85(0.37)$ \\
\hline
\end{tabular}

Values are expressed as mean (standard deviation)

AoRoot $=$ aortic root; AscAo $=$ ascending aorta; b-Lateral $=$ basal lateral wall; b-Septal $=$ basal septal wall; $L V=$ left ventricle; $d L /$ $\mathrm{dt}_{\max }=$ maximum rate of change in length; $\mathrm{dr} / \mathrm{dt}_{\max }=$ maximum rate of change in radius; $\mathrm{dV} / \mathrm{dt}_{\max }=$ maximum rate of volume change; $C_{\mathrm{d}-\max }=$ maximum rate of change during diastole

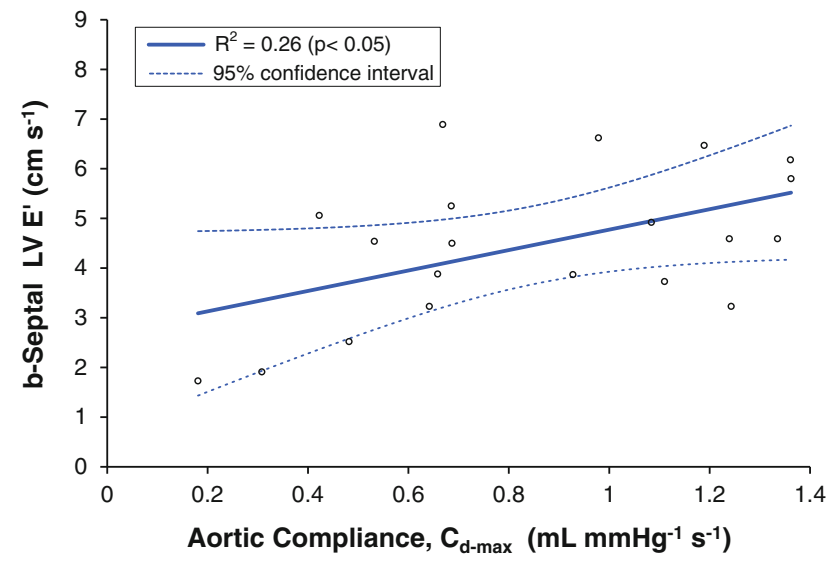

Fig. 4 Results of linear regression analysis of left ventricular basalseptal early diastole $\left(\mathrm{E}^{\prime}\right)$ vs maximum rate of change in ascending aortic compliance during early diastole

impact diastolic function, highlighting the multifactorial nature of diastolic dysfunction. ${ }^{33,34}$

Our study's main purpose was to explore the feasibility of STI to measure the physical properties of the proximal aorta as a starting point for future research. The strength of association between our measure of aortic compliance and diastolic function $\left(R^{2}=0.26\right)$ was similar to those previously reported, where $\mathrm{R}^{2}$-values ranged from $0.22-0.59 .^{7-12}$ We consider this a surrogate indicator that our method

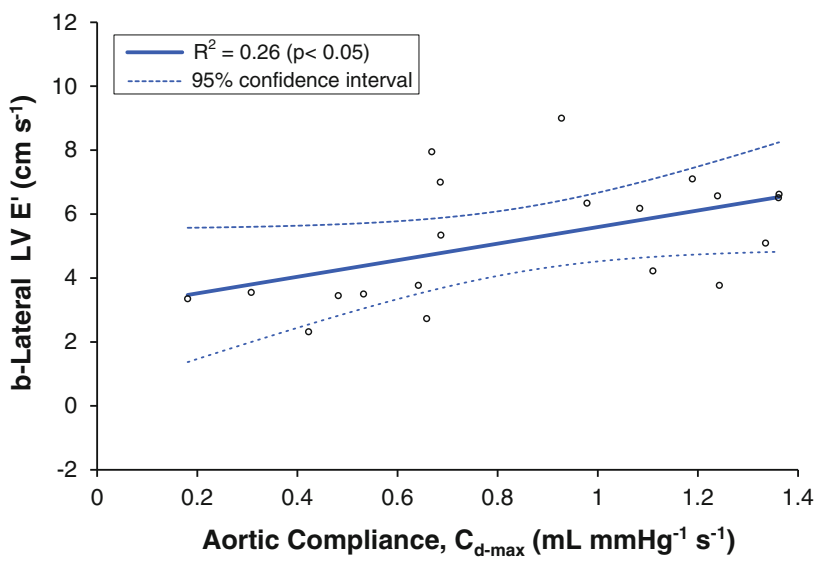

Fig. 5 Results of linear regression analysis of left ventricular basallateral early diastole $\left(\mathrm{E}^{\prime}\right)$ vs maximum rate of change in ascending aortic compliance during early diastole

reliably and accurately measures proximal aortic compliance. Unfortunately, since there is currently no accepted gold standard for noninvasively measuring instantaneous aortic compliance, it is not possible to comment definitively on the validity of our results. At best, our technique can be evaluated based on its underlying assumptions and their limitations.

First, due to the retrospective nature of our study, we did not have a pressure wave tracing to use for the calculation of compliance. Instead, our method relied on a $\mathrm{dV} / \mathrm{dt}$ that was normalized to the mean arterial pressure, synchronizing the time values on the TEE images and our electronic anesthetic record. This functioned as control for differences in patients' blood pressure at the time of TEE image acquisition, minimizing its impact as a confounding variable when measuring compliance. Previous work has suggested that aortic pressure may contribute less than changes in volume with regard to indices of aortic compliance $^{23}$; therefore, the impact of lacking simultaneous invasive pressure measurements should be minimal.

Second, we measured the radial and longitudinal velocities of the aortic wall by tracking their echocardiographic images using STI. Tissue velocities calculated from STI have been validated using sonomicrometry and magnetic resonance imaging ${ }^{35}$; however, it is still subject to error caused by out-of-plane movement. The aorta itself does not remain fixed within the chest during the cardiac cycle and its motion can be interpreted by the STI software as aortic wall velocity. This translational velocity can then add or subtract to the true velocity of the expanding or contracting aortic vascular tissue. Using STI-based aortic wall strain or strain rates instead of velocities would prevent this error and should be considered in future research.

Third, the computer algorithms for calculating STI strain rates are vendor specific. ${ }^{36}$ Software analysis will 
also vary between images acquired from a transthoracic approach and those acquired from a transesophageal approach. ${ }^{37}$ As a consequence, the absolute values for aortic radial and longitudinal strain or velocity will not necessarily be the same with different devices, producing different values for aortic $\mathrm{dV} / \mathrm{dt}$ and possibly different results.

Finally, the mathematical model we used to calculate aortic compliance functionally regards the aorta as a geometric cylinder with equal lengths on all sides, a circular cross section, and a constant diameter along its full length., clearlythis is not the case. We attempted to minimize the discrepancies by dividing the proximal aorta into two segments,

Future studies using STI to analyze ventricular-vascular coupling should simultaneously assess the relationship using traditional diastolic methodology, such as pulse-wave velocities and TDI. They should also compare STI-based analysis with alternative measures of aortic compliance, such as the beta stiffness index or distensibility. Our study is proof of a concept, and more study is required. In future this study will need ti be reproduced using invasive blood pressure monitoring, allowing for more accurate measurement of aortic compliance. Aortic compliance also needs to be compared with a more inclusive measure of afterload, such as characteristic impedance, for a better understanding of the relative role of each in diastolic function.

We present a novel method that could potentially allow the noninvasive study of the physical behaviour of the aorta in real time, dynamically, and with greater detail than previously reported. Speckle tracking show promise in providing new insights into ventricular function, aortic mechanics in vivo, and the interaction between these two anatomically connected structures.

Disclosure statement None declared.

Competing interests None declared.

\section{References}

1. Matyal R, Skubas NJ, Shernan SK, Mahmood F. Perioperative assessment of diastolic dysfunction. Anesth Analg 2011; 113 : 449-72.

2. Swaminathan M, Nicoara A, Phillips-Bute BG, et al. Utility of a simple algorithm to grade diastolic dysfunction and predict outcome after coronary artery bypass graft surgery. Ann Thorac Surg 2011; 91: 1844-50.

3. Bernard F, Denault A, Babin D, et al. Diastolic dysfunction is predictive of difficult weaning from cardiopulmonary bypass. Anesth Analg 2001; 92: 291-8.

4. Flu WJ, van Kuijk JP, Hoeks SE, et al. Prognostic implications of asymptomatic left ventricular dysfunction in patients undergoing vascular surgery. Anesthesiology 2010; 112: 1316-24.

5. Matyal R, Hess PE, Subramaniam B, et al. Perioperative diastolic dysfunction during vascular surgery and its association with postoperative outcome. J Vasc Surg 2009; 50: 70-6.
6. Xu-Cai YO, Brotman DJ, Phillips CO, et al. Outcomes of patients with stable heart failure undergoing elective noncardiac surgery. Mayo Clin Proc 2008; 83: 280-8.

7. Triantafyllidi H, Rizos I, Rallidis L, et al. Aortic distensibility associates with increased ascending thoracic aorta diameter and left ventricular diastolic dysfunction in patients with coronary artery ectasia. Heart Vessels 2010; 25: 187-94.

8. Suh SY, Kim EJ, Choi CU, et al. Aortic upper wall tissue Doppler image velocity: relation to aortic elasticity and left ventricular diastolic function. Echocardiography 2009; 26: 1069-74.

9. Karamitsos TD, Karvounis HI, Didangelos TP, et al. Aortic elastic properties are related to left ventricular diastolic function in patients with type 1 diabetes mellitus. Cardiology 2008; 109: 99-104.

10. Tsioufis $C$, Chatzis D, Dimitriadis $K$, et al. Left ventricular diastolic dysfunction is accompanied by increased aortic stiffness in the early stages of essential hypertension: a TDI approach. J Hypertens 2005; 23: 1745-50.

11. Mottram PM, Haluska BA, Leano R, Carlier S, Case C, Marwick $T H$. Relation of arterial stiffness to diastolic dysfunction in hypertensive heart disease. Heart 2005; 91: 1551-6.

12. Eren M, Gorgulu S, Uslu N, Celik S, Dagdeviren B, Tezel T. Relation between aortic stiffness and left ventricular diastolic function in patients with hypertension, diabetes, or both. Heart 2004; 90: 37-43.

13. Marwick TH. Measurement of strain and strain rate by echocardiography: ready for prime time? J Am Coll Cardiol 2006; 47: 1313-27.

14. Park SJ, Oh JK. Correlation between LV regional strain and LV dyssynchrony assessed by 2D STE in patients with different levels of diastolic dysfunction. Echocardiography 2010; 27: 1194-204.

15. Kim H, Shin HW, Son J, et al. Two-dimensional strain or strain rate findings in mild to moderate diastolic dysfunction with preserved ejection fraction. Heart Vessels 2011; 26: 39-45.

16. Yip GW, Zhang Q, Xie JM, et al. Resting global and regional left ventricular contractility in patients with heart failure and normal ejection fraction: insights from speckle-tracking echocardiography. Heart 2011; 97: 287-94.

17. Larsson $M$, Bjallmark A, Lind B, et al. Wave intensity wall analysis: a novel noninvasive method to measure wave intensity. Heart Vessels 2009; 24: 357-65.

18. Petrini J, Yousry M, Rickenlund A, et al. The feasibility of velocity vector imaging by transesophageal echocardiography for assessment of elastic properties of the descending aorta in aortic valve disease. J Am Soc Echocardiogr 2010; 23: 985-92.

19. Oishi Y, Mizuguchi Y, Miyoshi H, Iuchi A, Nagase N, Oki T. A novel approach to assess aortic stiffness related to changes in aging using two-dimensional strain imaging. Echocardiography 2008; 25: 941-5.

20. $L i J K$. The Arterial Circulation: Physical Principles and Clinical Applications. Totowa, New Jersey: Humana Press; 2000.

21. Shrout PE, Fleiss JL. Intraclass correlations: uses in assessing rater reliability. Psychol Bull 1979; 86: 420-8.

22. Altman DG, Bland JM. Measurement in medicine: the analysis of method comparison studies. Journal of the Royal Statistical Society: Series D (The Statistician) 1983; 32: 307-17.

23. Kawasaki T, Sasayama S, Yagi S, Asakawa T, Hirai T. Noninvasive assessment of the age related changes in stiffness of major branches of the human arteries. Cardiovasc Res 1987; 21: 678-87.

24. Lacombe F, Dart A, Dewar E, et al. Arterial elastic properties in man: a comparison of echo-Doppler indices of aortic stiffness. Eur Heart J 1992; 13: 1040-5.

25. Nagueh SF, Appleton CP, Gillebert TC, et al. Recommendations for the evaluation of left ventricular diastolic function by echocardiography. J Am Soc Echocardiogr 2009; 22: 107-33. 
26. Shanewise JS, Cheung AT, Aronson, et al. ASE/SCA Guidelines for performing a comprehensive intraoperative multiplane transesophageal echocardiography examination: recommendations of the American Society of Echocardiography Council for Intraoperative Echocardiography and the Society of Cardiovascular Anesthesiologists Task Force for Certification in Perioperative Transesophageal Echocardiography. J Am Soc Echocardiogr 1999; 12: 884-900.

27. Pavlopoulos H, Nihoyannopoulos EP. Strain and strain rate deformation parameters: from tissue Doppler to 2D speckle tracking. Int J Cardiovasc Imaging 2008; 24: 479-91.

28. Kort $S$, Madahar P, Ajmera A, Brown DL. Mitral annular velocities generated by speckle tracking imaging: reproducibility and correlation with tissue Doppler velocities. Echocardiography 2010; 27: 637-43.

29. Imbalzano $E$, Zito $C$, Carerj $S$, et al. Left ventricular function in hypertension: new insight by speckle tracking echocardiography. Echocardiography 2011; 28: 649-57.

30. Leite-Moreira AF, Correia-Pinto J, Gillebert TC. Afterload induced changes in myocardial relaxation: a mechanism for diastolic dysfunction. Cardiovasc Res 1999; 43: 344-53.

31. Kawaguchi M, Hay I, Fetics B, Kass DA. Combined ventricular systolic and arterial stiffening in patients with heart failure and preserved ejection fraction: implications for systolic and diastolic reserve limitations. Circulation 2003; 107: 714-20.

32. Surucu H, Tatli E, Boz H, Meric M. The association between left ventricular diastolic dysfunction and increased aortic stiffness can be explained by possible neurohumoral mechanisms. Echocardiography 2010; 27: 275-81.

33. Phan TT, Frenneaux $M$. The pathophysiology of diastolic heart failure. F1000 Biol Reports 2010; DOI: 10.3410/B2-16.

34. Kass DA, Bronzwaer JG, Paulus WJ. What mechanisms underlie diastolic dysfunction in heart failure? Circ Res 2004; 94: 153342.

35. Amundsen BH, Helle-Valle T, Edvardsen T, et al. Noninvasive myocardial strain measurement by speckle tracking echocardiography: validation against sonomicrometry and tagged magnetic resonance imaging. J Am Coll Cardiol 2006; 47: 789-93.

36. Manovel A, Dawson D, Smith B, Nihoyannopoulos $P$. Assessment of left ventricular function by different speckle-tracking software. Eur J Echocardiogr 2010; 11: 417-21.

37. Marcucci CE, Samad Z, Rivera J, et al. A comparative evaluation of transesophageal and transthoracic echocardiography for measurement of left ventricular systolic strain using speckle tracking. J Cardiothorac Vasc Anesth 2012; 26: 17-25. 